\title{
An Order Level Inventory Model for Deteriorating Items with Time - Quadratic Demand and Partial Backlogging
}

\author{
J. Jagadeeswari ${ }^{1}$, P. K. Chenniappan ${ }^{2, *}$ \\ ${ }^{1}$ Department of Mathematics, Sri Ramakrishna Engineering College, Coimbatore, Tamilnadu, India \\ ${ }^{2}$ Department of Mathematics, Government Arts College (Autonomous), Coimbatore, Tamilnadu, India \\ Corresponding author: pkchenniappan@gmail.com
}

Received August 08, 2014; Revised August 15, 2014; Accepted October 21, 2014

\begin{abstract}
In this paper, a deterministic inventory model is developed for deteriorating items in which shortages are allowed and partially backlogged. The backlogging rate is assumed to be dependent on the length of the waiting time for the next replenishment. The longer the waiting time is, the smaller the backlogging rate would be. The deterioration rate is constant and demand rate is assumed to be time quadratic. Numerical example and sensitivity analysis are evaluated for validating the proposed model.
\end{abstract}

Keywords: inventory, deteriorating items, shortages, time - quadratic demand, partial backlogging

Cite This Article: J. Jagadeeswari, and P. K. Chenniappan, "An Order Level Inventory Model for Deteriorating Items with Time - Quadratic Demand and Partial Backlogging." Journal of Business and Management Sciences, vol. 2, no. 3A (2014): 17-20. doi: 10.12691/jbms-2-3A-2.

\section{Introduction}

In the last three decades, the models for inventory replenishment policies involving time-varying demand patterns have received the attention of several researchers. The fundamental result in the development of economic order quantity model with time-varying demand patterns is that of Donaldson (1979) [11] who established the classical no-shortage inventory model with a linear trend in demand over a known and finite horizon. However, his procedure was too complex and tedious in computing. The complexity of Donaldson's approach has led to the development of heuristic methods. Dave and Patel (1981) [12] first considered the inventory model for deteriorating items with time-varying demand. They considered a linear increasing demand over a finite horizon and a constant deterioration rate. Sachan (1984) [13] extended Dave and Patel's model to allow shortages.

Researchers have developed economic order quantity models that focused on deteriorating items with timevarying demand and shortages. Silver et al. (1998) [1] explained inventory management and production planning and scheduling. Raafat (1991) [2] described survey of literature on continuously deteriorating inventory model. Chang and Dye (1999) [3] explored an EOQ model for deteriorating items with time varying demand and partial backlogging. Goyal and Giri (2001) [4] presented recent trends in modeling of deteriorating inventory. Teng and Chang (2005) [5] defined economic production quantity models for deteriorating items with price and stock dependent demand. Singh and Singh (2007) [6] presented an EOQ inventory model with Weibull distribution deterioration, Ramp type demand and Partial Backlogging.
Singh et al. (2009) [7] extended an EOQ model for perishable items with power demand and partial backlogging. You, (2005) [8] derived Inventory policy for products with price and time dependent demands. Pareek, Mishra, and Rani (2009) [9] presented an inventory model for time dependent deteriorating item with salvage value and shortages and Hamid (1989) [10] explored replenishment schedule for deteriorating items with time proportional demand. Lin et al. (2000) [14] explained an EOQ model for deteriorating items with time - varying demand and shortages. Hariga (1996) [15] defined optimal EOQ models for deteriorating items with time - varying demand. In practice, some customers would like to wait for backlogging during the shortage period, but the others would not. Consequently, the opportunity cost due to lost sales should be considered.

In this paper, backlogging rate is assumed to be a fixed fraction of demand rate during the shortage period. However, in some inventory system, for many stock such as fashionable commodities, the length of the waiting time for the next replenishment becomes a major factor for determining whether the backlogging will be accepted or not. The longer the waiting time is, the smaller the backlogging rate would be. Therefore, the backlogging rate is variable and is dependent on the waiting time for the next replenishment. Here an attempt has been made to model the situation where the demand rate is a timequadratic function and the items deteriorate at a constant rate with partial backlogging.

\section{Notations and Assumptions}

The mathematical model in this paper is developed on the basis of the following notations and assumptions. 


\subsection{Notations}

A - Ordering cost per order

$\mathrm{h}$ - Inventory carrying cost per unit per unit time

s - Shortage cost per unit per unit time

$l$ - Opportunity cost due to lost sales per unit

$\mathrm{r}$ - Purchase cost per unit

$t_{1}$ - the time at which the inventory level reaches zero, $\mathrm{t}_{1} \geq 0$

$t_{2}$ - the length of period during which shortages are allowed, $\mathrm{t}_{2} \geq 0$

$\mathrm{T}-\left(=\mathrm{t}_{1}+\mathrm{t}_{2}\right)$ the length of cycle time

$I_{1}(t)$ - the level of positive inventory at time $t, 0 \leq t \leq t_{1}$

$I_{2}(t)$ - the level of negative inventory at time $t, t_{1} \leq t \leq t_{1}$ $+t_{2}$

$\theta$ - Deterioration rate, a fraction of the on-hand inventory

IM - Maximum inventory level during [0, T]

IB - Maximum inventory level during shortage period

$\mathrm{R}(\mathrm{t})$ - Demand rate at any time $\mathrm{t} \geq 0$

\subsection{Assumptions}

A single item is considered with a constant rate of deterioration.

The replenishment occurs instantaneously at an infinite rate.

A deteriorated unit is neither repaired nor replaced during a given cycle

The deterministic demand rate $\mathrm{R}(\mathrm{t})$ varies quadratic with time, i.e., $\mathrm{R}(\mathrm{t})=\mathrm{a}+\mathrm{bt}+\mathrm{ct}^{2}$, where $\mathrm{a}, \mathrm{b}$ and $\mathrm{c}$ are constants such that a, b, c $>0$.

Shortages are allowed and partially backlogged.

During stock out period, the backlogging rate is variable and is dependent on the length of the waiting time for the next replenishment. The backlogging rate is assumed to be $\frac{1}{1+\alpha(T-t)}$ where the backlogging parameter $\alpha$ is a positive constant and $(\mathrm{T}-\mathrm{t})$ is waiting time $\left(\mathrm{t}_{1} \leq \mathrm{t} \leq \mathrm{T}\right)$.

\section{Mathematical Model}

The rate of change of inventory during positive stock period $\left[0, t_{1}\right]$ and shortage period $\left[\mathrm{t}_{1}, \mathrm{~T}\right]$ is governed by the differential equations

$$
\begin{gathered}
\frac{d I_{1}(t)}{d t}+\theta I_{1}(t)=-\left(a+b t+c t^{2}\right), 0 \leq t \leq t_{1} \\
\frac{d I_{2}(t)}{d t}=\frac{-\left(a+b t+c t^{2}\right)}{1+\alpha(T-t)}, t_{1} \leq t \leq T
\end{gathered}
$$

With boundary conditions,

$\mathrm{I}_{1}(\mathrm{t})=\mathrm{I}_{2}(\mathrm{t})=0$ at $\mathrm{t}=\mathrm{t}_{1}$ and $\mathrm{I}_{1}(\mathrm{t})=\mathrm{IM}$ at $\mathrm{t}=0$.

\section{Analytical Solution}

During the period $\left[0, \mathrm{t}_{1}\right]$, the inventory depletes due to the deterioration and demand. Hence the inventory level at any time during $\left[0, t_{1}\right]$ is described by equation (1) which is a linear ordinary differential equation of first order and its integrating factor is $\mathrm{e}^{\theta \mathrm{t}}$. Multiplying both sides of (1) by $\mathrm{e}^{\theta \mathrm{t}}$ and then integrating over $[0, \mathrm{t}]$ and applying the boundary condition $\mathrm{I}_{1}\left(\mathrm{t}_{1}\right)=0$ we have

$$
\begin{aligned}
& I_{1}(t)=-\frac{a}{\theta}-\frac{b}{\theta}\left(t-\frac{1}{\theta}\right)-\frac{c}{\theta}\left[\left(t-\frac{1}{\theta}\right)^{2}+\frac{1}{\theta^{2}}\right]+ \\
& e^{\theta\left(t_{1}-t\right)}\left\{\frac{a}{\theta}+\frac{b}{\theta}\left(t_{1}-\frac{1}{\theta}\right)+\frac{c}{\theta}\left[\left(t_{1}-\frac{1}{\theta}\right)^{2}+\frac{1}{\theta^{2}}\right]\right\} \\
& 0 \leq \mathrm{t} \leq \mathrm{t}_{1}
\end{aligned}
$$

During the interval $\left[\mathrm{t}_{1}, \mathrm{~T}\right]$ the inventory level depends on demand and a fraction of demand is backlogged. The state of inventory during $\left[\mathrm{t}_{1}, \mathrm{~T}\right]$ is represented by the equation (2) and it's solution is given by

$$
\begin{aligned}
& I_{2}(t)=\left\{\frac{a}{\alpha}+\frac{b\left[1+\alpha\left(t_{1}+t_{2}\right)\right]}{\alpha^{2}}+\frac{c\left[1+\alpha\left(t_{1}+t_{2}\right)\right]^{2}}{\alpha^{3}}\right\} \\
& \log \left[\frac{1+\alpha\left(t_{1}+t_{2}-t\right)}{1+\alpha t_{2}}\right]+\frac{b\left(t-t_{1}\right)}{\alpha} \\
& +\frac{c\left(t-t_{1}\right)}{\alpha^{2}}\left[1+\frac{3 \alpha\left(t_{1}+t_{2}\right)}{2}\right], \\
& \mathrm{t}_{1} \leq \mathrm{t} \leq \mathrm{t}_{1}+\mathrm{t}_{2}
\end{aligned}
$$

The total cost per replenishment cycle consists of the following components:

Inventory holding cost per cycle =

$$
h \int_{0}^{t_{1}} I_{1}(t) d t \frac{h}{\theta^{4}}\left[\begin{array}{l}
a \theta^{2}\left(e^{t_{1} \theta}-t_{1} \theta-1\right) \\
+\frac{b \theta}{2}\left(2 e^{t_{1} \theta}\left(t_{1} \theta^{2}-1\right)-t_{1}^{2} \theta^{2}+1\right) \\
+\frac{c}{3}\left(3 e^{t_{1} \theta}\left(t_{1}^{2} \theta^{2}-2 t_{1} \theta+2\right)-t_{1}^{3} \theta^{3}-5\right)
\end{array}\right]
$$

Cost of deterioration $=\frac{r h}{\theta^{3}}=$

$$
\left[\begin{array}{l}
a \theta^{2}\left(e^{t_{1} \theta}-t_{1} \theta-1\right) \\
+\frac{b \theta}{2}\left(2 e^{t_{1} \theta}\left(t_{1} \theta^{2}-1\right)-t_{1}^{2} \theta^{2}+1\right) \\
+\frac{c}{3}\left(3 e^{t_{1} \theta}\left(t_{1}^{2} \theta^{2}-2 t_{1} \theta+2\right)-t_{1}^{3} \theta^{3}-5\right)
\end{array}\right]
$$

Backordered cost per cycle

$$
\begin{aligned}
& s \int_{t_{1}}^{t_{1}+t_{2}}\left[-I_{2}(t)\right] d t \\
& =\left\{\begin{array}{l}
\frac{a}{\alpha}+\frac{b\left[1+\alpha\left(t_{1}+t_{2}\right)\right]}{\alpha^{2}} \\
+\frac{c\left[1+\alpha\left(t_{1}+t_{2}\right)\right]^{2}}{\alpha^{3}}
\end{array}\right\} \\
& \left\{t_{2}+\frac{1}{\alpha} \log \frac{1}{1+\alpha t_{2}}\right\} \\
& \left.-\frac{t_{2}^{2}}{6 \alpha^{2}}\left[3 b \alpha+2 c \alpha\left(3 t_{1}+2 t_{2}\right)+c\right]\right\}
\end{aligned}
$$


Lost sales cost per cycle $=$

$$
\begin{aligned}
& l \int_{t_{1}}^{t_{1}+t_{2}}\left[1-\frac{1}{1+\alpha\left(t_{1}+t_{2}-t\right)}\right]\left(a+b t+c t^{2}\right) d t=
\end{aligned}
$$

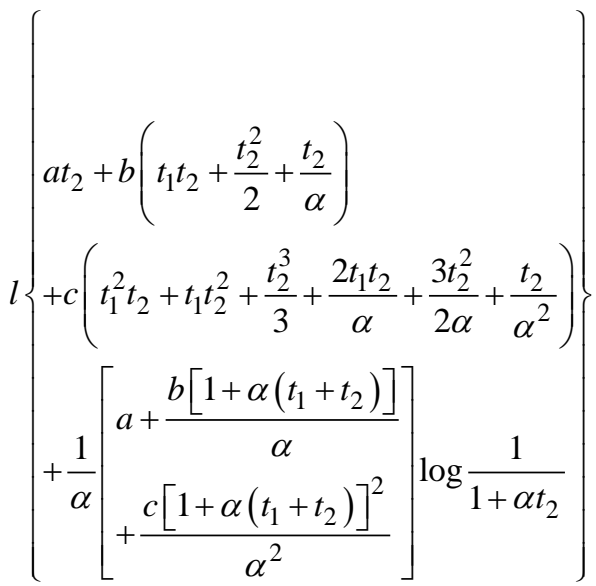

When $\mathrm{t}=0$ the level of inventory is maximum and it is denoted by IM. Then from equation (3)

$$
\begin{aligned}
& I M=-\frac{a}{\theta}+\frac{b}{\theta^{2}}-\frac{2 c}{\theta^{3}} \\
& +e^{\theta t_{1}}\left[\frac{a}{\theta}+\frac{b}{\theta}\left(t_{1}-\frac{1}{\theta}\right)+\frac{c}{\theta}\left[\left(t_{1}-\frac{1}{\theta}\right)^{2}+\frac{1}{\theta^{2}}\right]\right]
\end{aligned}
$$

The maximum backordered inventory is obtained at $\mathrm{t}=$ $\mathrm{t}_{1}+\mathrm{t}_{2}$ and is denoted by IB. Thus from equation (4)

$$
\begin{aligned}
& I B=-I_{2}\left(t_{1}+t_{2}\right) \\
& =-\left\{\left\{\begin{array}{l}
\left\{\frac{a}{\alpha}+\frac{b\left[1+\alpha\left(t_{1}+t_{2}\right)\right]}{\alpha^{2}}+\frac{c\left[1+\alpha\left(t_{1}+t_{2}\right)\right]^{2}}{\alpha^{3}}\right\} \\
\log \frac{1}{1+\alpha t_{2}}+\frac{b t_{2}}{\alpha}+\frac{3 c t_{2}^{2}}{2 \alpha}+\frac{2 c t_{1} t_{2}}{\alpha}+\frac{c t_{2}}{\alpha^{2}}
\end{array}\right\}\right.
\end{aligned}
$$

Thus the order size during total time interval $(0, T)$ is given by

$$
\mathrm{Q}=\mathrm{IM}+\mathrm{IB}
$$

Purchase cost per cycle $=\mathrm{rQ}=$

$$
r\left\{\begin{array}{l}
-\frac{a}{\theta}+\frac{b}{\theta^{2}}-\frac{2 c}{\theta^{3}} \\
\left.+e^{\theta t_{1}\left[\frac{a}{\theta}+\frac{b}{\theta}\left(t_{1}-\frac{1}{\theta}\right)+\frac{c}{\theta}\left[\left(t_{1}-\frac{1}{\theta}\right)^{2}+\frac{1}{\theta^{2}}\right]\right.}\right] \\
{\left[\begin{array}{l}
\left.\frac{a}{\alpha}+\frac{b\left[1+\alpha\left(t_{1}+t_{2}\right)\right]}{\alpha^{2}}\right] \\
+\frac{c\left[1+\alpha\left(t_{1}+t_{2}\right)\right]^{2}}{\alpha^{3}}
\end{array}\right] \log \left(1+\alpha t_{2}\right)} \\
-\frac{b t_{2}}{\alpha}-\frac{3 c t_{2}^{2}}{2 \alpha}-\frac{2 c t_{1} t_{2}}{\alpha}-\frac{c t_{2}}{\alpha^{2}}
\end{array}\right\}
$$

Therefore the Total cost (TC) per time unit is given by, $T C=\frac{1}{\left(t_{1}+t_{2}\right)}$ [Ordering cost + Inventory holding cost +
Cost of deterioration + Backordered cost + Lost sales cost + Purchase cost]

$$
\begin{aligned}
& =\frac{1}{\left(t_{1}+t_{2}\right)}\left[A+\frac{h}{\theta^{4}}\left[\begin{array}{l}
a \theta^{2}\left(e^{t_{1} \theta}-t_{1} \theta-1\right) \\
+\frac{b \theta}{2}\left(2 e^{t_{1} \theta}\left(t_{1} \theta^{2}-1\right)-t_{1}^{2} \theta^{2}+1\right) \\
+\frac{c}{3}\left(3 e^{t_{1} \theta}\left(t_{1}^{2} \theta^{2}-2 t_{1} \theta+2\right)-t_{1}^{3} \theta^{3}-5\right)
\end{array}\right]\right. \\
& +\frac{r h}{\theta^{3}}\left[\begin{array}{l}
a \theta^{2}\left(e^{t_{1} \theta}-t_{1} \theta-1\right) \\
+\frac{b \theta}{2}\left(2 e^{t_{1} \theta}\left(t_{1} \theta^{2}-1\right)-t_{1}^{2} \theta^{2}+1\right) \\
+\frac{c}{3}\left(3 e^{t_{1} \theta}\left(t_{1}^{2} \theta^{2}-2 t_{1} \theta+2\right)-t_{1}^{3} \theta^{3}-5\right)
\end{array}\right] \\
& +\mathrm{S}\left\{\begin{array}{l}
\left\{\frac{a}{\alpha}+\frac{b\left[1+\alpha\left(t_{1}+t_{2}\right)\right]}{\alpha^{2}}+\frac{c\left[1+\alpha\left(t_{1}+t_{2}\right)\right]^{2}}{\alpha^{3}}\right\} \\
\left\{t_{2}+\frac{1}{\alpha} \log \frac{1}{1+\alpha t_{2}}\right\}-\frac{t_{2}^{2}}{6 \alpha^{2}}\left[3 b \alpha+2 c \alpha\left(3 t_{1}+2 t_{2}\right)+c\right]
\end{array}\right\}
\end{aligned}
$$$$
+l\left\{a t_{2}+b\left(t_{1} t_{2}+\frac{t_{2}^{2}}{2}+\frac{t_{2}}{\alpha}\right)+c\left(\begin{array}{l}
t_{1}^{2} t_{2}+t_{1} t_{2}^{2}+\frac{t_{2}^{3}}{3} \\
+\frac{2 t_{1} t_{2}}{\alpha}+\frac{3 t_{2}^{2}}{2 \alpha}+\frac{t_{2}}{\alpha^{2}}
\end{array}\right)\right.
$$

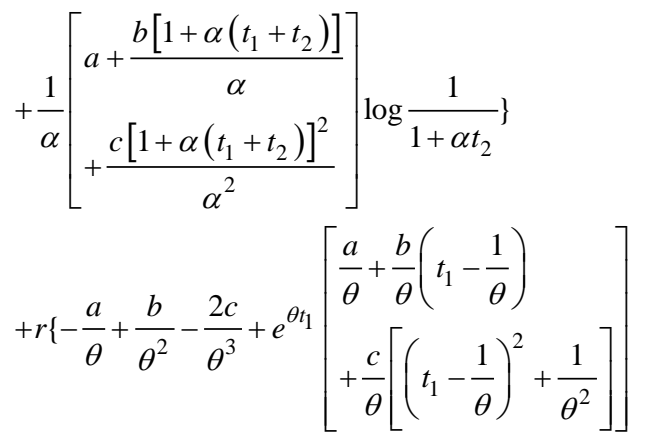

$+\left[\frac{a}{\alpha}+\frac{b\left[1+\alpha\left(t_{1}+t_{2}\right)\right]}{\alpha^{2}}+\frac{c\left[1+\alpha\left(t_{1}+t_{2}\right)\right]^{2}}{\alpha^{3}}\right]$

$\left.\left.\log \left(1+\alpha t_{2}\right)-\frac{b t_{2}}{\alpha}-\frac{3 c t_{2}^{2}}{2 \alpha}-\frac{2 c t_{1} t_{2}}{\alpha}-\frac{c t_{2}}{\alpha^{2}}\right\}\right]$

The necessary condition for the total cost per time unit to be a minimum is

$$
\frac{\partial T C}{\partial t_{1}}=0 \text { and } \frac{\partial T C}{\partial t_{2}}=0
$$

Provided

$$
\left(\frac{\partial^{2} T C}{\partial t_{1}^{2}}\right)\left(\frac{\partial^{2} T C}{\partial t_{2}^{2}}\right)-\left(\frac{\partial^{2} T C}{\partial t_{1} \partial t_{2}}\right)>0
$$

\section{Numerical Example}

Consider an inventory system with the following parameter in proper units: $\mathrm{A}=250$,

$\mathrm{h}=0.05, \mathrm{~s}=1.2, \mathrm{l}=1.5, \alpha=8, \theta=0.005, \mathrm{a}=25, \mathrm{~b}=$ $20, \mathrm{c}=15$. The computed optimal value of TC is 92.53 . 


\section{Sensitivity Analysis}

The variation in the parameters is as follows:

Table 1. Sensitivity Analysis of the Total Cost for the Parameters a, b, $\mathbf{c}, \boldsymbol{\alpha}$ and $\boldsymbol{\theta}$

\begin{tabular}{|c|c|c|c|c|c|}
\hline Parameter & Value & $t_{2}$ & $t_{2}$ & $\mathrm{TC}$ & \% Change in TC \\
\hline \multirow{4}{*}{ a } & 20 & 5.32 & 0.05 & 92.42 & 0.12 \\
\hline & 23 & 5.31 & 0.05 & 92.48 & 0.05 \\
\hline & 25 & 5.3 & 0.05 & 92.53 & 0 \\
\hline & 26 & 5.3 & 0.05 & 92.75 & 0.23 \\
\hline \multirow{4}{*}{ b } & 16 & 5.72 & 0.05 & 85.72 & 7.36 \\
\hline & 18 & 5.52 & 0.05 & 89.16 & 3.64 \\
\hline & 20 & 5.3 & 0.05 & 92.53 & 0 \\
\hline & 21 & 5.2 & 0.05 & 93.12 & 0.63 \\
\hline \multirow{4}{*}{ C } & 15 & 5.88 & 0.05 & 82.63 & 10.70 \\
\hline & 16 & 5.61 & 0.05 & 88.21 & 4.67 \\
\hline & 17 & 5.3 & 0.05 & 92.53 & 0 \\
\hline & 18 & 5.28 & 0.05 & 94.67 & 2.31 \\
\hline \multirow{4}{*}{$\alpha$} & 7.5 & 5.3 & 0.05 & 92.32 & 0.23 \\
\hline & 8 & 5.3 & 0.05 & 92.53 & 0 \\
\hline & 8.5 & 5.3 & 0.04 & 92.59 & 0.06 \\
\hline & 9 & 5.31 & 0.04 & 92.66 & 0.14 \\
\hline \multirow{4}{*}{$\theta$} & 0.004 & 5.32 & 0.05 & 91.12 & 1.52 \\
\hline & 0.0045 & 5.31 & 0.05 & 91.72 & 0.88 \\
\hline & 0.005 & 5.3 & 0.05 & 92.53 & 0 \\
\hline & 0.0055 & 5.3 & 0.05 & 92.95 & 0.45 \\
\hline
\end{tabular}

From Table 1, it is observed that the total cost increases if the parameters a, b, c, $\alpha$ and $\theta$ are increased. Also the parameters $\mathrm{a}, \mathrm{b}$ and $\mathrm{c}$ are more sensitive than $\alpha$ and $\theta$.

\section{Conclusion}

In this paper, we have developed an order quantity model for deteriorating items with time - quadratic demand and partial backlogging. In particular, the backlogging rate is considered to be a decreasing function of the waiting time for the next replenishment. This assumption is more realistic in the market.

\section{References}

[1] Silver, E.A., Pyke, D.F. and Peterson, R. (1998). Inventory Management and Production Planning and Scheduling. John Wiley and Sons, New York.

[2] Raafat, E. (1991). Survey of Literature on continuously deteriorating inventory model. Journal of Operational Research Society, 42: 27-37.

[3] Chang, H.J. and Dye, C.Y. (1999). An EOQ model for deteriorating items with time varying demand and partial backlogging. Journal of Operational Research Society, 50: 11761182.

[4] Goyal, S.K. and Giri, B.C. (2001). Recent trends in modeling of deteriorating inventory. European Journal of Operational Research, 134: 1-16.

[5] Teng, J.T. and Chang, C.T. (2005). Economic production quantity models for deteriorating items with price and stock dependent demand. Computers and Operational Research, 32: 297-308.

[6] Singh, S.R. and Singh, T.J. (2007). An EOQ Inventory model with Weibull Distribution deterioration, Ramp type demand and Partial Backlogging. Indian Journal of Mathematics and Mathematical Sciences, 3 (2): 127-137.

[7] Singh, T.J., Singh, S.R. and Dutt, R. (2009), An EOQ model for perishable items with power demand and partial backlogging, International Journal of Production Economics, 15 (1): 65-72.

[8] You, S.P. (2005). Inventory policy for products with price and time dependent demands. Journal of Operational Research Society, 56: 870-873.

[9] Pareek, S., Mishra, V.K. and Rani, S. (2009). An Inventory model for time dependent deteriorating item with salvage value and shortages. Mathematics today, 25: 31-39.

[10] Hamid, B. (1989). Replenishment schedule for deteriorating items with time proportional demand. Journal of Operations Research Society, 40: 75-81.

[11] Donaldson, W.A. (1979). Inventory replenishment policy for a linear trend in demand-an analytical solution. Operational Research Quarterly, 28: 663-670.

[12] Dave, U. and Patel, L.K. (1981). (T, $\mathrm{S}_{\mathrm{i}}$ ) policy inventory model for deteriorating items with time proportional demand. Journal of Operational Research Society, 32: 137-142.

[13] Sachan, R.S. (1984). On (T, $\mathrm{S}_{\mathrm{i}}$ ) inventory policy model for deteriorating items with time proportional demand. Journal of Operational Research Society, 35: 1013-1019.

[14] Lin, C., Tan, B. and Lee, W.C. (2000). An EOQ model for deteriorating items with time-varying demand and shortages. International Journal of System Science, 31 (3): 390-400.

[15] Hariga, M. (1996). Optimal EOQ models for deteriorating items with time-varying demand. Journal of Operational Research Society, 47: 1228-1246. 